\title{
$\pi$-Conjugated Microporous Polymer Films: Designed Synthesis, Conducting Properties, and Photoenergy Conversions
}

\author{
Cheng Gu, Ning Huang, Youchun Chen, Leiqiang Qin, Hong Xu, Shitong Zhang, Fenghong Li, \\ Yuguang Ma, and Donglin Jiang*
}

\begin{abstract}
Conjugated microporous polymers are a unique class of polymers that combine extended $\pi$-conjugation with inherent porosity. However, these polymers are synthesized through solution-phase reactions to yield insoluble and unprocessable solids, which preclude not only the evaluation of their conducting properties but also the fabrication of thin films for device implementation. Here, we report a strategy for the synthesis of thin films of $\pi$-conjugated microporous polymers by designing thiophene-based electropolymerization at the solution-electrode interface. High-quality films are prepared on a large area of various electrodes, the film thickness is controllable, and the films are used for device fabrication. These films are outstanding hole conductors and, upon incorporation of fullerenes into the pores, function as highly efficient photoactive layers for energy conversions. Our film strategy may boost the applications in photocatalysis, energy storage, and optoelectronics.
\end{abstract}

Advances over the past decade in polymer chemistry have had a substantial effect on the design of $\pi$-conjugated microporous polymers (CMPs) ${ }^{[1]}$ They show outstanding properties in gas storage,$^{[2]}$ sensing ${ }^{[3]}$ luminescence, ${ }^{[4]}$ catalysis, ${ }^{[5]}$ energy transfer, ${ }^{[6]}$ and electric energy storage. ${ }^{[7,8,9 a]}$ CMPs are currently synthesized through solution-phase polymerizations, including Suzuki reaction, ${ }^{[3 a, 4 b, 5 a, 6 a]}$ Sonogashira reactions, ${ }^{[2 \mathrm{~b}, \mathrm{~d}, \mathrm{e}, 5 \mathrm{~b}, 6 \mathrm{~b}, \mathrm{c}, 7]}$ Yamamoto reactions, ${ }^{[3 \mathrm{a}, 4 \mathrm{a}, 5 \mathrm{c}]}$ oxidative coupling reaction, ${ }^{[2 \mathrm{a}, \mathrm{c}, \mathrm{d}, 3 \mathrm{cc}]}$ cyclotrimerization reaction, ${ }^{[5 \mathrm{e}, 9]}$

[*] Dr. C. Gu, ${ }^{[+]}$N. Huang, ${ }^{[+]}$Dr. H. Xu, Prof. Dr. D. Jiang

Department of Materials Molecular Science

Institute for Molecular Science

National Institutes of Natural Sciences

5-1 Higashiyama, Myodaiji, Okazaki 444-8787 (Japan)

E-mail: jiang@ims.ac.jp

Y. Chen, S. Zhang, Prof. F. Li

State Key Laboratory of Supramolecular Structure and Materials

Jilin University, Changchun 130012 (P. R. China)

L. Qin, Prof. Y. Ma

State Key Laboratory of Luminescent Materials and Devices

Institute of Polymer Optoelectronic Materials and Devices

South China University of Technology

Guangzhou 510640 (P. R. China)

$\left.{ }^{+}\right]$These authors contributed equally to this work.

(2) Supporting information for this article is available on the WWW under http://dx.doi.org/10.1002/anie.201506570.

Of (C) 2015 The Authors. Published by Wiley-VCH Verlag GmbH \& Co. $\mathrm{KGaA}$. This is an open access article under the terms of the Creative Commons Attribution Non-Commercial License, which permits use, distribution and reproduction in any medium, provided the origina work is properly cited and is not used for commercial purposes.
Schiff-base reaction, ${ }^{[10]}$ phenazine ring-fusion reaction, ${ }^{[8]}$ and Friedel-Crafts reaction. ${ }^{[11]}$ These reactions covalently link organic building blocks into $\pi$-conjugated polymer skeletons. Owing to their crosslinked network structures, the vast majority of CMPs are obtained as insoluble and unprocessable solids, which preclude not only the evaluation of conducting properties but also the preparation of high-quality thin films for device applications. There are a few examples of solution processable CMPs, ${ }^{[12]}$ where films can be prepared by solution casting, but the incorporation of these materials into functional devices has not yet been demonstrated. Although a variety of CMPs with different $\pi$-structures have been reported, their conducting properties are still undetermined and their potentials for device applications remain unclear. The field of CMPs is currently facing two major challenges, that is, CMPs are not processable and their conductivity is unkown. These challenges need to be overcome for the further advance of the field. ${ }^{[1 \mathrm{~d}]}$

Recently, we have developed an electropolymerization method for the synthesis of porous polymers, ${ }^{[13]}$ which uses a solution-electrode interface for the simultaneous polymerization and deposition of porous polymer films on electrodes. However, this method has been explored only for monomers that have $\mathrm{N}$-substituted carbazole units as electropolymerization groups. These $\mathrm{N}$-substituted-carbazole-based systems result in a class of porous organic polymer films but they do not have a $\pi$-conjugated structure ${ }^{[13]}$ because of the interruption of $\pi$-conjugation by the $\mathrm{N}$-bonds. To overcome these limitations, we endeavored to explore new molecular systems that can form $\pi$-conjugated porous polymer films. Herein, we report the first synthesis of $\pi$-conjugated microporous polymer films, which are prepared on the large area of various electrodes with high quality and can be used for device fabrications. We show the controlled synthesis of thin films with different thicknesses of nanometer precision and highlight their outstanding properties, including their porosities, band gaps, conductivity, and their functions as photoactive layers for solar cells.

The key concept in designing thiophene-based building blocks is that each thiophene subunit contains only one reactive position (Figure 1a, blue arrows) for electropolymerization by $\mathrm{C}-\mathrm{C}$ bond formation (Figure $1 \mathrm{~b}$ ). We designed monomers with multiple thiophene units on a focal aromatic benzene moiety; this multi-arm alignment makes possible the formation of porous $\pi$-skeletons as predicted by the calculated optimal elementary one-pore structures (Figure 1c). We demonstrated this new strategy by using two typical thiophene structures; one is the ring-fused thiophene, namely benzotrithiophene (BTT), which has a planar conformation, 
a)

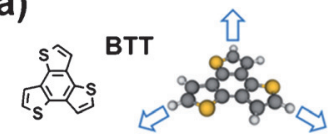

b)

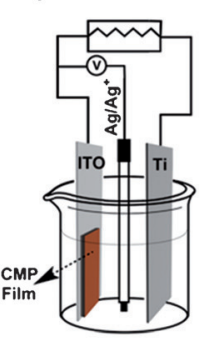

c)
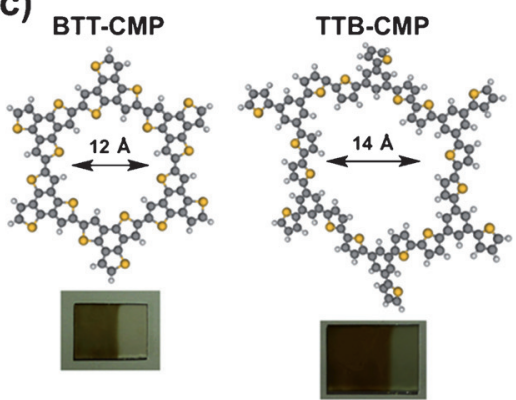

d)

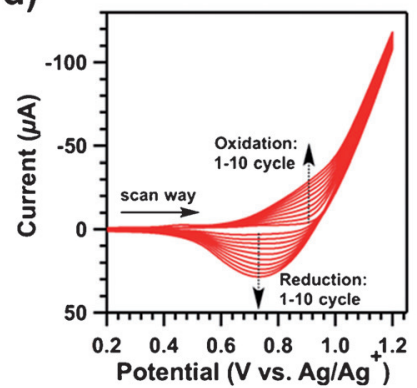

f)

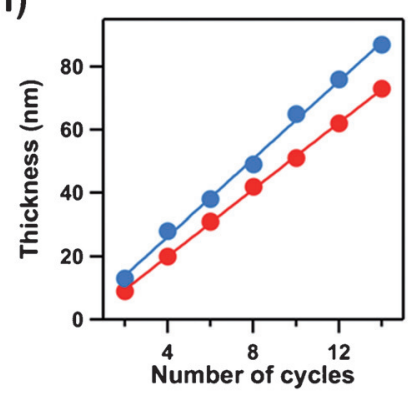

h)

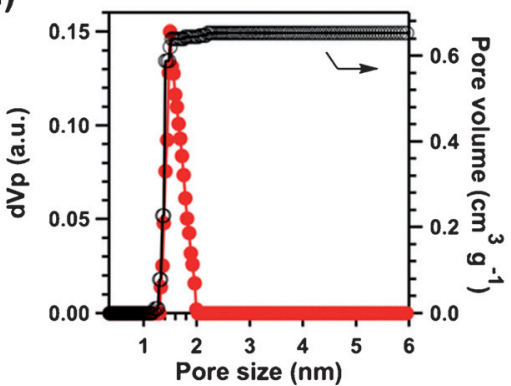

e)

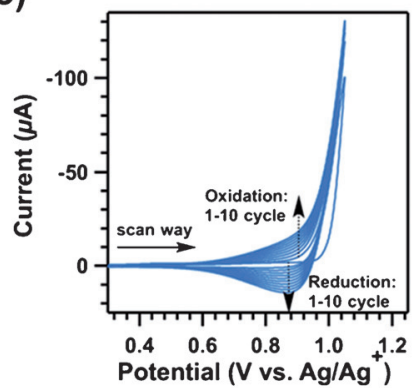

g)

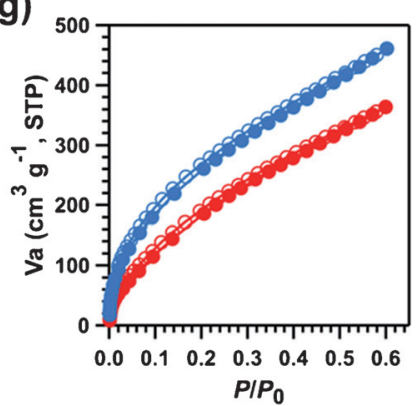

i)

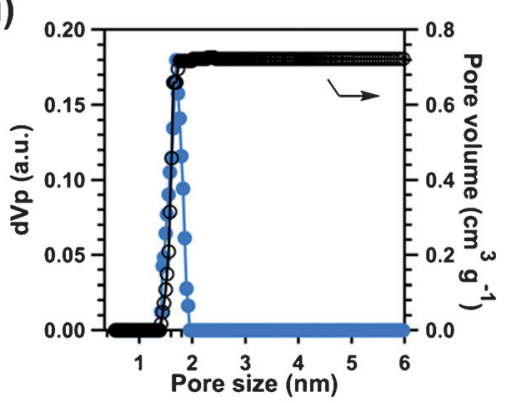

Figure 1. a) Structure of thiophene-based monomers BTT and TTB; BTT is planar whereas TTB is propeller-shaped (black: carbon, yellow: sulfur, white: hydrogen). The blue arrows indicate the carbon positions for the $\mathrm{C}-\mathrm{C}$ bond formation in the polymerization reaction. b) Setup of the three-electrode electrochemical cell for the polymerization of monomers and the deposition of CMP films on ITO. c) Elementary pore structures of the BTT-CMP and TTB-CMP films (inset: photos of the films). d,e) Cyclic voltammetry profiles of 10 cycles of d) BTT and e) TTB. f) Dependence of the film thickness on the number of scan cycles (red: BTT-CMP film, blue: TTB-CMP film). g) Kr sorption isotherm curves collected at $77 \mathrm{~K}$ for the BTT-CMP film (red curve) and the TTB-CMP film (blue curve; solid circles: adsorption, open circles: desorption). $h$,i) Pore size and pore-size distribution profiles of the h) BTT-CMP and i) TTBCMP films.

and the other is a ring-substituted thiophene, that is, 1,3,5tri(2-thienyl)-benzene (TTB), which suggests a propellershaped structure. In the CMPs, the BTT and TTB units occupy the knot segments of the networks (Figure 1c) and the monomer structures play a vital role in directing the growth of

porous skeletons and controlling their $\pi$ electronic, conducting, and photovoltaic properties.

We set up a three-electrode electropolymerization system using indium tin oxide (ITO), poly(3,4-ethylenedioxythiophene):poly(4-styrenesulfonate)

(PEDOT:PSS) coated ITO, or glassy carbon as the working electrodes, a titanium plate as the counter electrode, and $\mathrm{Ag} / \mathrm{Ag}^{+}$as the reference electrode (Figure $1 \mathrm{~b})$. Under optimal reaction conditions, propylene carbonate (PC) was used as the solvent, $n \mathrm{Bu}_{4} \mathrm{NClO}_{4}(0.1 \mathrm{M})$ was used as the electrolyte, and the concentration of BTT or TTB was set to $2 \times 10^{-2}$ or $3 \times 10^{-3} \mathrm{M}$, respectively. The electropolymerization was conducted by cyclic voltammetry $(\mathrm{CV})$ scanning in the optimized potential range from -0.8 to $1.2 \mathrm{~V}$ for BTT and from -0.8 to $1.05 \mathrm{~V}$ for TTB, respectively. Polymerization occurs only at the solution-electrode interface; this method precludes the formation of CMP particles in bulk solution. As the polymerization proceeded, the electrode gradually became brown-red in color, as identified by the naked eye. During the polymerization the CMP films were simultaneously deposited at the electrodes.

Figure $1 \mathrm{~d}$ and $1 \mathrm{e}$ present the $\mathrm{CV}$ profiles for BTT and TTB, respectively, for a consecutive scan of 10 cycles at a rate of $0.05 \mathrm{~V} \mathrm{~s}^{-1}$ (see Figure S1 in the Supporting Information). One cycle required only $80 \mathrm{~s}$ to complete under the optimal conditions. With respect to the CV cycles, an oxidative band was observed when the applied potential exceeded $0.58 \mathrm{~V}$ for both BTT and TTB; in the potential range from 0.58 to $0.96 \mathrm{~V}$ for BTT (Figure $1 \mathrm{~d}$ ) and from 0.58 to $1.02 \mathrm{~V}$ for TTB (Figure 1e), the networks of the films oxidized. The currents associated with these bands increased as the number of cycle scans was increased. A similar increasing trend was also observed for the reduction peaks. These increases indicated that polymerization of the monomers and formation of the CMP films proceeded cleanly and rapidly upon successive CV scans.

A distinct feature of the electropolymerization used to produce CMP films is that this method makes possible well-defined control over the film thickness. We prepared films at scan cycles of 2, 4, 6, 8, 10,12, and 14 and measured the film thickness using a profilometer. Figure $1 \mathrm{f}$ presents plots of the thickness versus the cycle number. The 
thickness of both CMP films exhibited a linear dependency on the cycle number. On the basis of the slopes, the thickness of the BTT-CMP films (red curve) increase by $5.3 \mathrm{~nm}$ per cycle, whereas an increase of $6.2 \mathrm{~nm}$ per cycle was observed for the TTB-CMP films (blue curve). The tunability of the film thickness determines the compatibility with various device applications; in this thiophene-based electropolymerization systems, the film thickness can be controlled by simply adjusting the number of scan cycles.

Polymerization of BTT was observed by the disappearance of the C-H deformation band at $851 \mathrm{~cm}^{-1}$ of the thiophene unit and the appearance of a new band at $928 \mathrm{~cm}^{-1}$ assignable to the C-C linker at the 2-position of the dithiophene units (Table S1, Figure S2). Polymerization of TTB resulted in the disappearance of the band at $851 \mathrm{~cm}^{-1}$ assigned to the $\mathrm{C}-\mathrm{H}$ deformation of the thiophene moiety of TTB and the appearance of a new band at $1158 \mathrm{~cm}^{-1}$ assignable to the $\mathrm{C}-\mathrm{C}$ linkers at the 2-position of the dithiophene units in the TTB-CMP films (Table S1, Figure S2). The HR-TEM images show that both the BTT-CMP and TTB-CMP films consist of homogeneous microporous textures with pore sizes less than $2 \mathrm{~nm}$ (Figure S3). To observe the morphology of the CMPs in the films, we performed atomic force microscopy (AFM) measurements. The BTTCMP films comprised two-dimensional thin plates with widths of approximately $300-400 \mathrm{~nm}$, whereas the TTB-CMP films were composed of oval-shaped objects with sizes of 200 $300 \mathrm{~nm}$ (Figure S4). Both films exhibited smooth surface morphologies; the root-mean-square (RMS) roughness of the $60 \mathrm{~nm}$-thick BTT-CMP and TTB-CMP films was 1.24 and $1.78 \mathrm{~nm}$, respectively. These low RMS roughness values of thin films satisfy the requirements of optoelectronic devices.

We investigated the porosity of the films by performing $\mathrm{Kr}$ adsorption isotherm measurements at $77 \mathrm{~K}$. For this purpose, we synthesized micrometer-thick films using an electrolysis method. We prepared the films on several ITO electrodes, and placed these films on ITO electrodes in the sample tube of the adsorption device for measurement. The BTT-CMP and TTB-CMP films exhibited similar adsorption profiles (Figure 1g). The BTT-CMP film exhibited a BrunauerEmmett-Teller (BET) surface area of $1152 \mathrm{~m}^{2} \mathrm{~g}^{-1}$, whereas the TTB-CMP film exhibited a BET surface area of $1405 \mathrm{~m}^{2} \mathrm{~g}^{-1}$. Using the nonlocal density function theory method, the pore size distribution and pore volume were calculated to be $1.51 \mathrm{~nm}$ and $0.65 \mathrm{~cm}^{3} \mathrm{~g}^{-1}$ for the BTT-CMP films and $1.70 \mathrm{~nm}$ and $0.72 \mathrm{~cm}^{3} \mathrm{~g}^{-1}$ for the TTB-CMP films, respectively (Figure $1 \mathrm{~h}, \mathrm{i}$, Table $\mathrm{S} 1$ ).

We used two methods to evaluate the band gap of the CMP films. First, the optical band gap was estimated from the onset edges of the electronic absorption spectra. The BTTCMP films exhibited an onset edge at $650 \mathrm{~nm}$, and the TTBCMP films exhibited an onset edge at $570 \mathrm{~nm}$ (Figure S5); these values correspond to band gaps of 1.91 and $2.18 \mathrm{eV}$, respectively. Second, the electrochemical band gap was evaluated on the basis of CV measurements. The CMP films on glassy carbon electrodes were measured in a threeelectrode electrochemical cell in the absence of the monomer. The BTT-CMP films exhibited onset oxidative and reductive potentials at 0.66 and $-1.34 \mathrm{~V}$, respectively (Figure $2 \mathrm{a}$, red curve), which correspond to the highest occupied molecular orbital (HOMO) and the lowest unoccupied molecular orbital (LUMO) levels of -5.32 and $-3.32 \mathrm{eV}$, respectively (Figure $2 \mathrm{~b}$, Table S1). Thus, the electrochemical band gap is $2.00 \mathrm{eV}$. Using the same method, the HOMO and LUMO levels of the TTB-CMP films were evaluated to be -5.54 and $-3.19 \mathrm{eV}$ on the basis of their onset potentials of 0.88 and $-1.74 \mathrm{~V}$, respectively (Figure $2 \mathrm{a}$, blue curve). Therefore, the TTB-CMP films have a band gap of $2.35 \mathrm{eV}$ (Figure $2 \mathrm{~b}$ ). These low-band-gap materials can be used in semiconducting and optoelectronic applications.

The hole-conducting properties were investigated using the space-charge-limited current (SCLC) technique, ${ }^{[14]}$ with a device structure of ITO/PEDOT:PSS/CMP film/ $/ \mathrm{MoO}_{3} / \mathrm{Al}$ (Figure 2c, inset). For this purpose, we conducted polymerization on the ITO/PEDOT:PSS electrode to form $60 \mathrm{~nm}$ thick CMP films, on which $10 \mathrm{~nm} \mathrm{MoO}_{3}$ and $100 \mathrm{~nm} \mathrm{Al}$ were vacuum deposited. The hole mobility was determined by fitting the dark current to the model of a single-carrier SCLC, defined as $J=9 \varepsilon_{0} \varepsilon_{\mathrm{\rho}} \mu_{\mathrm{h}} V^{2} / 8 d^{3}$, where $J$ is the current density, $\varepsilon_{0}$ is the permittivity of free space, $\varepsilon_{\mathrm{r}}$ is the material relative permittivity, $V$ is the effective voltage, and $d$ is the thickness of the active layer, respectively. Figure $2 \mathrm{c}$ shows the plots of $J^{1 / 2}$ versus $V$. Both CMP films exhibited linear correlations; their hole mobility $\mu_{\mathrm{h}}$ was deduced on the basis of the slope. Notably, the BTT-CMP film (red curve) exhibited a hole mobility as high as $7.34 \times 10^{-4} \mathrm{~cm}^{2} \mathrm{~V}^{-1} \mathrm{~s}^{-1}$, which is among the highest reported for $\pi$-conjugated polymers measured using the same technique. ${ }^{[14]}$ In contrast, the hole mobility of the TTB-CMP film (blue curve) was estimated to be $1.01 \times$ $10^{-4} \mathrm{~cm}^{2} \mathrm{~V}^{-1} \mathrm{~s}^{-1}$. Thus, the BTT-CMP films with planar BTT units greatly facilitate hole transport over the $\pi$ network.

The preparation of CMP films using electropolymerization has several advantages. The method is a high-throughput synthesis because the films were formed only on the electrodes; no polymer powder was observed in solution. This method is efficient because it produced a thin film in several seconds or minutes; the solution-phase synthesis of CMP powders requires several hours or days. The electropolymerization did not require any catalysts and was conducted at room temperature in air, while the synthesis of bulk CMPs usually requires specific catalysts, high temperatures, and an inert atmosphere. Although a large number of CMPs have been reported to date, their semiconducting properties remain unclear. Our results unambiguously indicate that CMPs can be designed as highly conductive films for device implementation.

Unlike other porous materials, CMPs are structurally unique in that they make possible the combination of extended $\pi$-conjugation and porosity. ${ }^{[1]}$ We further investigated their function as photoactive layer for photoenergy conversion. For this purpose, we directly polymerized the monomers on ITO/PEDOT:PSS electrodes to form CMP films. The resulting electrodes were then placed on a spin coater; 1,2-dichlorobenzene solution of fullerene $(50 \mu \mathrm{L})$ was subsequently dropped onto the CMP films and was allowed to stand for 10 minutes, followed by spin coating at $800 \mathrm{rpm}$ for 1 minute. We chose $\mathrm{C}_{60}$ as the electron acceptor (Figure $2 \mathrm{~b}$ ), whose diameter $(0.7 \mathrm{~nm})$ is smaller than the pore sizes 
a)

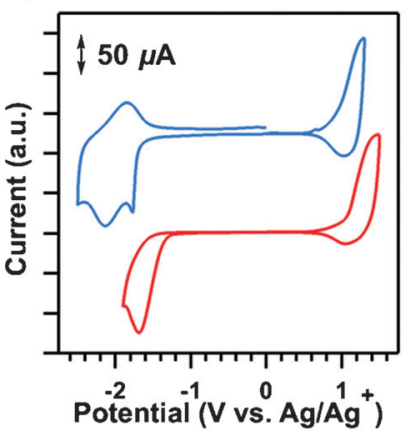

d)

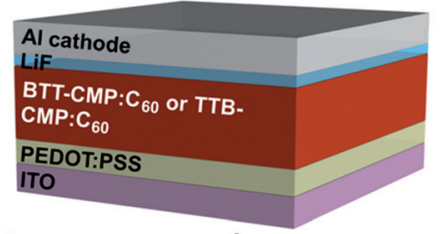

e) $h v$

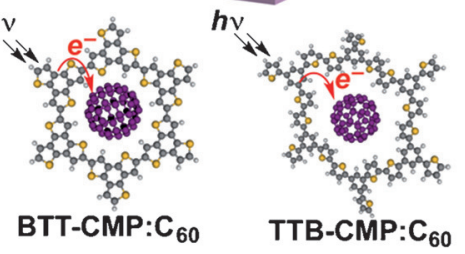

b)

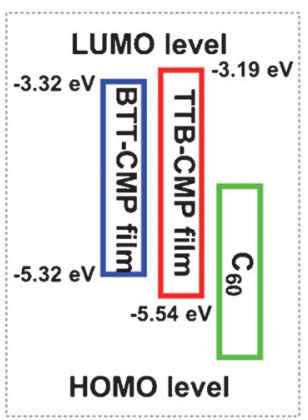

f)

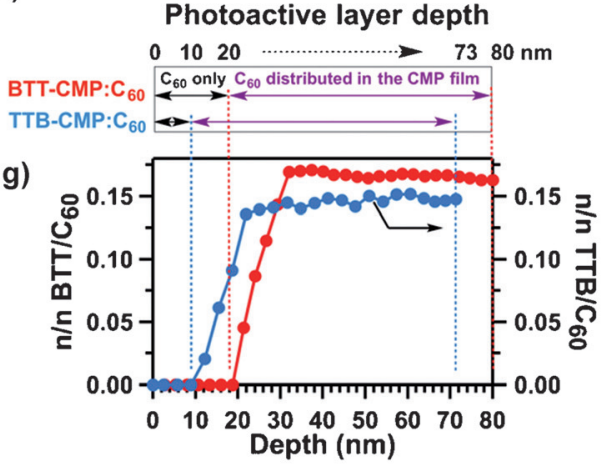

c)

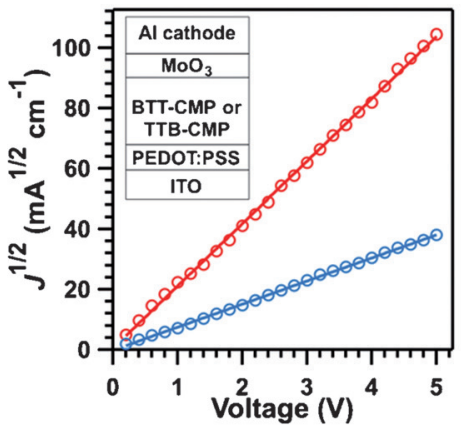

h)

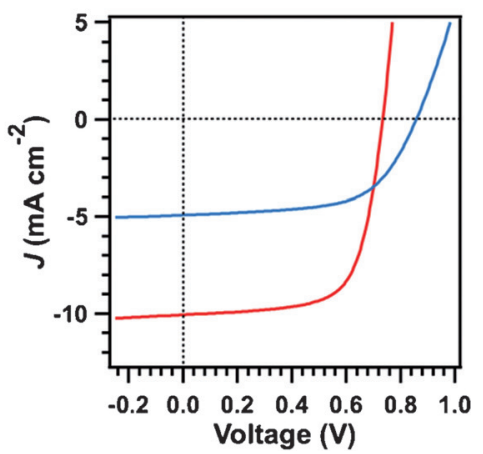

Figure 2. a) Cyclic voltammetry profiles of the $60 \mathrm{~nm}$-thick BTT-CMP (red curve) and TTB-CMP (blue curve) films. b) HOMO-LUMO levels of the BTT-CMP and TBB-CMP films compared with that of $\mathrm{C}_{60}$. C) Plots of $j^{1 / 2}$ versus the effective voltage of the BTT-CMP (red curve) and TTB-CMP (blue curve) film devices (inset: device configuration of SCLC measurements). d) Device configuration of solar cells using BTT-CMP: $C_{60}$ or TTB$\mathrm{CMP}: \mathrm{C}_{60}$ as photoactive layers. e) Basic structure of the CMP skeletons and the $\mathrm{C}_{60}$ dopants (purple: $\mathrm{C}_{60}$ ) involved in the photoactive layer. f) Depth-dependent distribution of $\mathrm{C}_{60}$ in the photoactive layers. The top $10 \mathrm{~nm}$ (for TTB-CMP: $\mathrm{C}_{60}$ ) and $20 \mathrm{~nm}$ (for BTT-CMP: $\mathrm{C}_{60}$ ) of the photoactive layers consist only of $\mathrm{C}_{60}$; under these top layers, $\mathrm{C}_{60}$ is homogeneously distributed in the $60 \mathrm{~nm}$-thick CMP films. g) Plots of the molar ratio of sulfur in BTT (red curve) or TTB (blue curve) to $C_{60}$ in the photoactive layer versus the layer depth. $h$ ) $J-V$ curves of the solar cells with BTT-CMP: $\mathrm{C}_{60}$ (red curve) or TTB-CMP: $\mathrm{C}_{60}$ (blue curve) as the photoactive layer.

(Figure $2 \mathrm{f}, \mathrm{g}$ ) of the films. The cathode of $0.5 \mathrm{~nm} \mathrm{LiF}$ and $100 \mathrm{~nm} \mathrm{Al}$ were then deposited in vacuum onto the photoactive layers to construct solar cells with a configuration of ITO/PEDOT:PSS/CMP: $\mathrm{C}_{60}$ film/LiF/Al (Figure 2d, Figure S6).

We prepared CMP films with different thicknesses of 42.4, 63.6, 79.5, and $106.1 \mathrm{~nm}$ for BTT-CMP films and 43.4, 62.1, 80.6, and $99.2 \mathrm{~nm}$ for TTB-CMP films (Figure S6, Tables S2, S3), used different concentrations of $\mathrm{C}_{60}$ of $5,10,15$, and $20 \mathrm{mg} \mathrm{mL}^{-1}$ (Tables S4 and S5), and prepared more than 200 solar cells for each condition to optimize the photoactive layers (Figures S7 and S8). Under optimal conditions, the CMP film thickness was determined to be $60 \mathrm{~nm}$ for both CMPs and the $\mathrm{C}_{60}$ concentration was $10 \mathrm{mg} \mathrm{mL}^{-1}$. We employed ion-sputtered X-ray photoelectron spectroscopy to evaluate the ratio of the sulfur atoms of the CMP films to the carbon atoms of $\mathrm{C}_{60}$. Figure $2 \mathrm{f}$ and $\mathrm{g}$ summarizes the depth-dependent distribution of $\mathrm{C}_{60}$. The BTT-CMP: $\mathrm{C}_{60}$ films (Figure $2 \mathrm{~g}$, red curve) consist of a top $20 \mathrm{~nm}$ layer of $\mathrm{C}_{60}$, under which $\mathrm{C}_{60}$ is homogeneously distributed throughout the $60 \mathrm{~nm}$ thick CMP film, as indicated by a sharp increase in the sulfur content at $20 \mathrm{~nm}$ and an almost constant sulfur level over the depth from 20 to $80 \mathrm{~nm}$. A similar phenomenon was also observed for the TTB-CMP: $\mathrm{C}_{60}$ films, which contain a top $10 \mathrm{~nm}$ layer of $\mathrm{C}_{60}$, whereas the CMP film was also homogeneously doped with $\mathrm{C}_{60}$ (blue curve). The porous structure facilitates the homogeneous doping of $\mathrm{C}_{60}$ into the film, which significantly enhances the $\mathrm{p}-\mathrm{n}$ heterojunction interface.

Figure $2 \mathrm{~h}$ shows the performance of solar cells fabricated using the CMP: $\mathrm{C}_{60}$ films as photoactive layers. The cells with BTT-CMP: $\mathrm{C}_{60}$ photoactive layers (red curve) exhibited a power conversion efficiency (PCE) of $5.02 \%$ (open-circuit voltage $\left(V_{\mathrm{OC}}\right)=0.732 \mathrm{~V}$, short-circuit current $\left(J_{\mathrm{SC}}\right)=$ $10.05 \mathrm{~mA} \mathrm{~cm}^{-2}$, and fill factor $\left.(\mathrm{FF})=0.682\right)$. In contrast, the cells fabricated using the TTB-CMP: $\mathrm{C}_{60}$ films as photoactive layers (blue curve) exhibited a PCE of $2.55 \%\left(V_{\mathrm{OC}}=0.859 \mathrm{~V}\right.$, $J_{\mathrm{SC}}=4.91 \mathrm{~mA} \mathrm{~cm}^{-2}$, and $\left.\mathrm{FF}=0.605\right)$. The high $J_{\mathrm{SC}}$ value observed for the BTT-CMP: $\mathrm{C}_{60}$ cells is attributed to the higher hole mobility of the BTT-CMP films, whereas the high $V_{\mathrm{OC}}$ for the TTB-CMP: $\mathrm{C}_{60}$ devices originates from the lower HOMO energy level of the TTB-CMP films (Figure $2 \mathrm{~b}$ ). These results indicate that the semiconducting CMP films could serve as highly efficient photoactive layers for photoenergy conversion. To the best of our knowledge, the PCEs of the CMP films are the highest reported among solar cells containing porous polymers as a photoactive layer (Table S7). ${ }^{[15]}$ 
In summary, our findings introduce a useful strategy based on electropolymerization for the preparation of $\pi$-conjugated microporous polymer films. The thiophene-based molecular systems are high throughput and efficient for the synthesis of high-quality large-area thin films and make it possible to control the film thickness. In principle, our strategy is widely extendable to other thiophene-based monomers for the preparation of various porous polythiophene films. For the first time, the conducting properties of CMP materials were unambiguously revealed. The high-performance photovoltaic devices are encouraging and would inspire further structural explorations. The present film strategy is tolerated for the structural design of monomers; we anticipate that the CMP films may find a wide variety of applications, such as transistors, diodes, vapor sensors, photoelectrochemical water splitting ${ }^{[5 \mathrm{f}]}$ and energy storage.

\section{Acknowledgements}

This work was supported by a Grant-in-Aid for Scientific Research (A) (24245030) from MEXT of Japan. C.G. is an International Research Fellow of the Japan Society for the Promotion of Science (JSPS).

Keywords: conjugated microporous polymers - hole mobility . semiconductors $\cdot$ solar cells $\cdot$ thin films

How to cite: Angew. Chem. Int. Ed. 2015, 54, 13594-13598 Angew. Chem. 2015, 127, 13798-13802

[1] a) J.-X. Jiang, F. Su, A. Trewin, C. D. Wood, N. L. Campbell, H. Niu, C. Dickinson, A. Y. Ganin, M. J. Rosseinsky, Y. Z. Khimyak, A. I. Cooper, Angew. Chem. Int. Ed. 2007, 46, 8574-8578; Angew. Chem. 2007, 119, 8728-8732; b) A. I. Cooper, Adv. Mater. 2009, 21, $1291-1295$; c) Y. Xu, S. Jin, H. Xu, A. Nagai, D Jiang, Chem. Soc. Rev. 2013, 42, 8012-8031; d) A. G. Slater, A. I. Cooper, Science 2015, 348, 988.

[2] a) Y.-C. Zhao, T. Wang, L.-M. Zhang, Y. Cui, B.-H. Han, Polym. Chem. 2015, 6, 748-753; b) Q. Chen, D.-P. Liu, J.-H. Zhu, B.-H. Han, Macromolecules 2014, 47, 5926-5931; c) C. Zhang, L.-H. Peng, B. Li, Y. Liu, P.-C. Zhu, Z. Wang, D.-H. Zhan, B. Tan, X.-L. Yang, H.-B. Xu, Polym. Chem. 2013, 4, 3663-3666.

[3] a) X. Liu, Y. Xu, D. Jiang, J. Am. Chem. Soc. 2012, 134, 87388741 ; b) X. Wu, H. Li, B. Xu, H. Tong, L. Wang, Polym. Chem. 2014, 5, 4521-4525; c) Y. Zhang, S. A, Y. Zou, X. Luo, Z. Li, H. Xia, X. Liu, Y. Mu, J. Mater. Chem. A 2014, 2, 13422-13430; d) H. Bildirir, I. Osken, T. Ozturk, A. Thomas, Chem. Eur. J. 2015, 21, 9306-9311.

[4] a) Y. Xu, L. Chen, Z. Guo, A. Nagai, D. Jiang, J. Am. Chem. Soc. 2011, 133, 17622-17625; b) W. Zhao, X. Zhuang, D. Wu, F. Zhang, D. Gehrig, F. Laquai, X. Feng, J. Mater. Chem. A 2013, 1, 13878-13884.

[5] a) L. Chen, Y. Yang, D. Jiang, J. Am. Chem. Soc. 2010, 132, 9138-9143; b) C. Zhang, Y. Liu, B. Li, B. Tan, C.-F. Chen, H.-B. Xu, X.-L. Yang, ACS Macro Lett. 2012, 1, 190-193; c) N. Huang, Y. Xu, D. Jiang, Sci. Rep. 2014, 4, 7228; DOI: 10.1038/srep07228; d) J.-X. Jiang, C. Wang, A. Laybourn, T. Hasell, R. Clowes, Y. Z. Khimyak, J. Xiao, S. J. Higgins, D. J. Adams, A. I. Cooper, Angew. Chem. Int. Ed. 2011, 50, 1072-1075; Angew. Chem.
2011, 123, 1104 - 1107; e) P. Katekomol, J. Roeser, M. Bojdys, J. Weber, A. Thomas, Chem. Mater. 2013, 25, 1542-1548; f) R. S. Sprick, J.-X. Jiang, B. Bonillo, S. Ren, T. Ratvijitvech, P. Guiglion, M. A. Zwijnenburg, D. J. Adams, A. I. Cooper, J. Am. Chem. Soc. 2015, 137, 3265 - 3270.

[6] a) L. Chen, Y. Honsho, S. Seki, D. Jiang, J. Am. Chem. Soc. 2010, 132, 6742-6748; b) P. Zhang, K. Wu, J. Guo, C. Wang, ACS Macro Lett. 2014, 3, 1139-1144; c) V. M. Suresh, S. Bonakala, S. Roy, S. Balasubramanian, T. K. Maji, J. Phys. Chem. C 2014, 118, $24369-24376$.

[7] a) F. Xu, X. Chen, Z. Tang, D. Wu, R. Fu, D. Jiang, Chem. Commun. 2014, 50, 4788-4790; b) L. Wang, X. Feng, L. Ren, Q. Piao, J. Zhong, Y. Wang, H. Li, Y. Chen, B. Wang, J. Am. Chem. Soc. 2015, 137, 4920-4923.

[8] Y. Kou, Y. Xu, Z. Guo, D. Jiang, Angew. Chem. Int. Ed. 2011, 50, 8753-8757; Angew. Chem. 2011, 123, 8912-8916.

[9] a) L. Hao, B. Luo, X. Li, M. Jin, Y. Fang, Z. Tang, Y. Jia, M. Liang, A. Thomas, J. Yang, L. Zhi, Energy Environ. Sci. 2012, 5, 9747-9751; b) S. Yuan, B. Dorney, D. White, S. Kirklin, P. Zapol, L. Yu, D.-J. Liu, Chem. Commun. 2010, 46, 4547-4549.

[10] a) C. Xu, N. Hedin, J. Mater. Chem. A 2013, 1, 3406-3414; b) P. Pandey, A. P. Katsoulidis, I. Eryazici, Y. Wu, M. G. Kanatzidis, S. T. Nguyen, Chem. Mater. 2010, 22, 4974-4979; c) M. G. Rabbani, A. K. Sekizkardes, O. M. El-Kadri, B. R. Kaafaranic, H. M. El-Kaderi, J. Mater. Chem. 2012, 22, 25409-25417.

[11] a) S. Wang, L. Tan, C. Zhang, I. Hussain, B. Tan, J. Mater. Chem. A 2015, 3, 6542-6548; b) S. Xu, K. Song, T. Li, B. Tan, J. Mater. Chem. A 2015, 3, 1272-1278; c) B. Li, Z. Guan, X. Yang, W. D. Wang, W. Wang, I. Hussain, K. Song, B. Tan, T. Li, J. Mater. Chem. A 2014, 2, 11930-11939; d) Y. Luo, S. Zhang, Y. Ma, W. Wang, B. Tan, Polym. Chem. 2013, 4, 1126-1131; e) Y. Luo, B. Li, W. Wang, K. Wu, B. Tan, Adv. Mater. 2012, 24, 5703-5707; f) B. Li, R. Gong, Y. Luo, B. Tan, Soft Matter 2011, 7, 1091010916; g) B. Li, X. Huang, L. Liang, B. Tan, J. Mater. Chem. 2010, $20,7444-7450$.

[12] a) G. Cheng, T. Hasell, A. Trewin, D. J. Adams, A. I. Cooper, Angew. Chem. Int. Ed. 2012, 51, 12727-12731; Angew. Chem. 2012, 124, 12899-12903; b) X. Zhu, C. Tian, S. M. Mahurin, S.H. Chai, C. Wang, S. Brown, G. M. Veith, H. Luo, H. Liu, S. Dai, J. Am. Chem. Soc. 2012, 134, 10478-10484; c) G. Cheng, B. Bonillo, R. S. Sprick, D. J. Adams, T. Hasell, A. I. Cooper, $A d v$. Funct. Mater. 2014, 24, 5219-5224.

[13] a) C. Gu, Y. Chen, Z. Zhang, S. Xue, S. Sun, K. Zhang, C. Zhong, H. Zhang, Y. Pan, Y. Lv, Y. Yang, F. Li, S. Zhang, F. Huang, Y. Ma, Adv. Mater. 2013, 25, 3443-3448; b) C. Gu, N. Huang, J. Gao, F. Xu, Y. Xu, D. Jiang, Angew. Chem. Int. Ed. 2014, 53, 4850-4855; Angew. Chem. 2014, 126, 4950-4955.

[14] a) V. D. Mihailetchi, J. Wildeman, P. W. M. Blom, Phys. Rev. Lett. 2005, 94, 126602-126605; b) C. Cui, W.-Y. Wong, Y. Li, Energy Environ. Sci. 2014, 7, 2276-2284.

[15] a) J. Guo, Y. Xu, S. Jin, L. Chen, T. Kaji, Y. Honsho, M. A. Addicoat, J. Kim, A. Saeki, H. Ihee, S. Seki, S. Irle, M. Hiramoto, J. Gao, D. Jiang, Nat. Commun. 2013, 4, 2736; DOI: 10.1038/ ncomms3736; b) M. Dogru, M. Handloser, F. Auras, T. Kunz, D. Medina, A. Hartschuh, P. Knochel, T. Bein, Angew. Chem. Int. Ed. 2013, 52, 2920-2924; Angew. Chem. 2013, 125, 2992-2996; c) M. Calik, F. Auras, L. M. Salonen, K. Bader, I. Grill, M. Handloser, D. D. Medina, M. Dogru, F. Löbermann, D. Trauner, A. Hartschuh, T. Bein, J. Am. Chem. Soc. 2014, 136, $17802-$ 17807.

Received: July 16, 2015

Revised: August 2, 2015

Published online: September 29, 2015 